\title{
Analisis Pengaruh Work Family Conflict dan Beban Kerja Terhadap Stres Kerja Dalam Mempengaruhi Turnover Intention (Studi Pada Karyawan PT. Bank Negara Indonesia (Persero), Tbk Wilayah Semarang)
}

\author{
Nurul Imani Kurniawati, ${ }^{1, *}$, Riandhita Eri Werdani ${ }^{2}$, Robetmi Jumpakita Pinem ${ }^{3}$ \\ ${ }^{1,2}$ Manajemen Pemasaran, Sekolah Vokasi, Universitas Diponegoro \\ ${ }^{3}$ Departemen Administrasi Bisnis, Fakultas Ilmu Sosial dan Ilmu Politik, Universitas Diponegoro ${ }^{3}$ \\ *Email: niyanurulimani@gmail.com
}

\begin{abstract}
The purpose of this research is to investigate the effects of work family conflict, work stress, work load and turnover intention. The study was conducted at women workers in the PT. Bank BNI Tbk Semarang. The data is processed using the Structural Equation Modeling (SEM) by the application program of Analysis of Moment Structure (AMOS) version 18.0. According to the analysis, it is concluded as the followings: work family conflict has a positive effect on work stress $(C R=2.347)$; work load has a positive effect on work stress $(C R=4.472)$; work family conflict has a effect on turnover intention $(C R=2.084)$; work load has a positive effect on turnover intention $(C R=2.208)$ and work stress has a not effect on turnover intention (CR $=1.616$ )
\end{abstract}

Abstraksi Tujuan dari penelitian ini adalah untuk mengetahui pengaruh konflik keluarga kerja, stres kerja, beban kerja dan intensi turnover. Penelitian ini dilakukan pada pekerja wanita di PT. Bank BNI Tbk Semarang. Data diolah menggunakan Structural Equation Modeling (SEM) dibantu oleh program aplikasi Analysis of Moment Structure (AMOS) versi 18.0. Menurut analisis, disimpulkan sebagai berikut: work family conflict memiliki efek positif pada stres kerja $(\mathrm{CR}=2,347)$; beban kerja memiliki efek positif pada stres kerja $(\mathrm{CR}=4.472)$; work family conflict berpengaruh pada intensi turnover $(\mathrm{CR}=2.084)$; beban kerja berpengaruh positif terhadap intensi turnover $(\mathrm{CR}=2.208)$ dan stres kerja tidak berpengaruh terhadap intensi turnover $(\mathrm{CR}=1.616)$

Keywords: Turnover; Turnover intention; Work Family Conflict; Work Load; Work Stress

\section{Pendahuluan}

Pertumbuhan ekonomi, perkembangan teknologi, arus informasi, persaingan dan perubahan lingkungan bisnis yang begitu cepat terjadi, membawa banyak perubahan pada berbagai aspek kehidupan masyarakat. Salah satu perubahan besar yang terjadi adalah semakin meningkatnya jumlah wanita bekerja. Saat ini banyak perusahaanperusahaan besar yang mayoritas karyawannya adalah wanita.

Batasan peran antara pria dan wanita dalam dunia kerja semakin lama semakin terkikis akibat adanya pertumbuhan teknologi dan ilmu yang berkembang dengan pesat. Banyak wanita yang mulai sadar akan pentingnya pendidikan memilih untuk menuntut ilmu setinggi mungkin. Dengan memiliki pendidikan yang tinggi, banyak wanita memilih untuk menjadi wanita karir. Selain pendidikan ada banyak motif pendorong semakin banyaknya wanita bekerja, yakni untuk aktualisasi diri dimana wanita dapat mengekspresikan dirinya melalui cara yang kreatif dan produktif yang akan mengarah pada kebahagiaan dirinya, meningkatkan kepercayaan diri, ketrampilan dan kompetensi, kebutuhan untuk bersosialisasi dengan orang lain, dan pastinya untuk menambah finansial keluarga. Wanita bekerja juga cenderung mempunyai pikiran yang terbuka dan fleksibel terhadap segala perubahan yang terjadi, lebih dapat bersikap dinamis, energik, dan berwawasan luas. Menurut Richardus (2011) mengemukakan bahwa wanita bekerja bagi wanita selain untuk mendapatkan uang sebagai tambahan ekonomi juga terkait dengan kesadaran akan kedudukan wanita baik dalam keluarga 
Tabel 1. Research Gap

\begin{tabular}{|c|c|c|c|}
\hline No & $\begin{array}{l}\text { Permasalahan } \\
\text { (Hubungan } \\
\text { antar variable) }\end{array}$ & Research Gap & Penulis \\
\hline \multirow[t]{2}{*}{1} & $\begin{array}{l}\text { Pengaruh Beban } \\
\text { kerja terhadap }\end{array}$ & $\begin{array}{l}\text { a. Beban kerja memiliki pengaruh positif } \\
\text { terhadap Turnover intention }\end{array}$ & a. Abbasi, (2015) \\
\hline & $\begin{array}{l}\text { Turnover } \\
\text { intention }\end{array}$ & $\begin{array}{l}\text { b. Beban kerja tidak memiliki pengaruh } \\
\text { positif terhadap Turnover intention }\end{array}$ & b. Pradana dan Salehudin, (2013) \\
\hline 2. & $\begin{array}{l}\text { Pengaruh Work } \\
\text { family conflict } \\
\text { terhadap Stress }\end{array}$ & $\begin{array}{l}\text { a. Work family conflict memiliki pengaruh } \\
\text { positif terhadap stres kerja } \\
\text { b. Work family conflict tidak memiliki } \\
\text { pengaruh terhadap stres kerja }\end{array}$ & $\begin{array}{l}\text { a. Alsam et al. (2013); Gayyur dan } \\
\text { Jamal, (2013); Lu et al. (2017) } \\
\text { b. Aslam et al. (2011) }\end{array}$ \\
\hline 3. & $\begin{array}{l}\text { Pengaruh Beban } \\
\text { Kerja terhadap } \\
\text { Stress }\end{array}$ & $\begin{array}{l}\text { a. Beban kerja memiliki pengaruh positif } \\
\text { terhadap stres kerja } \\
\text { b. Beban Kerja tidak memiliki pengaruh } \\
\text { terhadap stres kerja }\end{array}$ & $\begin{array}{l}\text { a. Crouter et al., (2001) } \\
\text { b. Buckingham, (2004) }\end{array}$ \\
\hline \multirow[t]{2}{*}{4.} & $\begin{array}{l}\text { Pengaruh Work } \\
\text { family conflict } \\
\text { terhadap }\end{array}$ & $\begin{array}{l}\text { a. Work family conflict memiliki pengaruh } \\
\text { positif terhadap Turnover intention }\end{array}$ & $\begin{array}{l}\text { a. Alsam et al., (2013); Gayyur dan } \\
\text { Jamal, (2013); Lu et al., (2017); } \\
\text { Hang-Yue et al., (2005) }\end{array}$ \\
\hline & $\begin{array}{l}\text { Turnover } \\
\text { intention }\end{array}$ & $\begin{array}{l}\text { b. Work family conflict tidak memiliki } \\
\text { pengaruh terhadap Turnover Intention }\end{array}$ & $\begin{array}{l}\text { b. Aslam et al., (2011), Riley } \\
\text { (2006) dalam Alsam et al., (2013) }\end{array}$ \\
\hline \multirow[t]{2}{*}{5.} & $\begin{array}{l}\text { Pengaruh stress } \\
\text { terhadap } \\
\text { Turnover }\end{array}$ & $\begin{array}{l}\text { a. Stres memiliki pengaruh positif terhadap } \\
\text { Turnover intention }\end{array}$ & $\begin{array}{l}\text { a. Abbasi, (2015); Arshadi dan } \\
\text { Damiri, (2013); Lu et al., (2017); } \\
\text { Hang-Yue et al., (2005) }\end{array}$ \\
\hline & intention & $\begin{array}{l}\text { b. Stres tidak memiliki pengaruh terhadap } \\
\text { Turnover intention }\end{array}$ & b. Pradana dan Salehudin, (2013) \\
\hline
\end{tabular}

Sumber: berbagai sumber (2017)

maupun masyarakat sehingga menyebabkan wanita secara khusus perlu menguatkan kemampuan dan memberdayakan dirinya sendiri untuk bekerja.

Sehingga wanita akan menjalannya peran ganda sebagai seorang ibu rumah tangga dan istri dan sebagai seorang wanita bekerja atau dual career. Bertemunya dua peran sekaligus yang dialami seorang wanita akan menimbulkan banyak konflik dan tekanan psikologis karena akan sulit untuk menyeimbangkan kedua peran yang dialami. Hal inilah yang menjadi penyebab adanya konflik peran ganda (work family conflict). Menurut Boles et al., dalam Dian (2008) menyatakan bahwa work family conflict adalah konflik yang terjadi karena terdapat ketidakseimbangan peran antara tanggung jawab di tempat tinggal dengan di tempat kerja. Sedangkan menurut Greenhaus dan Beulell (1985, dalam Widyaningrum, 2013) menyatakan bahwa work family conflict adalah konflik yang terjadi pada individu akibat menanggung peran ganda baik dalam pekerjaan (work) maupun keluarga (family). Kecenderungan ini terjadi karena jam kerja dan beban pekerjaan yang dimiliki oleh seorang karyawan terlalu padat dimana seluruh perhatian dan pikiran terlalu tercurahkan pada satu peran saja. Konflik peran ganda akan lebih dirasakan lagi jika karyawan wanita sudah menikah karena kodrat mereka adalah mengurus rumah tangga dan anak-anaknya.

Pembagian peran antara keluarga dan pekerjaan menjadi sebuah problematika tersendiri yang banyak dihadapi oleh karyawan wanita. Meskipun banyak karyawan wanita yang sudah mempunyai berbagai macam cara untuk menyiasati hal tersebut, tetap saja timbul permasalahan yang terjadi yang akan menimbulkan tekanan psikologis pada dirinya. Tingkat stres kerja seorang karyawan selain dipengaruhi oleh work family conflict juga dipengaruhi beban kerja dalam pekerjaannya. Seperti yang dikemukakan oleh Suwatno (2014) bahwa beban kerja yang dirasakan seorang pegawai dapat merupakan sumber stres. Beban kerja yang berlebihan dan beban kerja yang terlalu sedikit dapat berpengaruh pada kondisi psikis karyawan wanita. Jika seorang karyawan wanita memiliki beban kerja yang terlalu berat maka akan menimbulkan tingkat stres yang tinggi 
dan menyebabkan hasil kerjanya tidak akan optimal. Stres kerja didefiniskan sebagai perasaan yang menekan atau perasaan tertekan yang dialami pegawai dalam menghadapi pekerjaan (Mangkunegara, 2008). Menurut Wallace (2005), stres yang tinggi bisa dipicu adanya work family conflict. Konflik yang biasa terjadi dalam sebuah perusahaan bila dibiarkan saja akan menimbulkan efek yang kurang baik bagi perusahaan dalam mencapai tujuan organisasinya, yakni akan berdampak pada penurunan kinerja karyawan yang pada akhirnya akan menurunkan produktifitas organisasi (Yang, 2000). Konflik yang berkepanjangan juga mampu memunculkan tekanan pada diri karyawan, sehingga akan menimbulkan stres yang tinggi (Nasrudin dan Kumaresan, 2006).

\section{Kajian Teori}

\section{Work Family Conflict}

Boles et al., (Dian, 2008) menyatakan bahwa konflik peran ganda (work family conflict) merupakan konflik yang terjadi karena terdapat ketidak-seimbangan peran mengenai tanggung jawab di tempat kerja dengan di tempat tinggal". Berdasarkan beberapa definisi di atas dapat dikatakan bahwa work family conflict terjadi akibat seseorang tidak mampu menyeimbangkan peran yang terjadi pada dirinya, baik itu peranan keluarga yang menekan peranan pekerjaan maupun peranan pekerjaan yang menekan peranan keluarga.

\section{Beban Kerja}

Menurut Schultz dan Schultz (2006) "beban kerja merupakan suatu kondisi dimana seorang karyawan melakukan pekerjaan yang terlalu sulit atau terlalu banyak pekerjaan dibandingkan dengan waktu yang tersedia". "Beban kerja karyawan harus disesuaikan dengan kuantitas maupun kualitas pekerjaan. Kuantitas pekerjaan berkaitan dengan banyaknya pekerjaan yang harus dikerjakan apakah terlalu banyak atau sedikit, kualitas pekerjaan berkaitan dengan kemampuan dan keahlian yang dibutuhkan untuk melakukan pekerjaan. Karena apabila pekerjaan tidak sebanding dengan kemampuan dan keahlian seorang karyawan dan waktu yang tersedia maka dapat menimbulkan stres (Ilyas, 2000).

\section{Stres Kerja}

Menurut Indrawan (2009) stres kerja dapat terjadi pada semua jenis dan kondisi pekerjaan, yang disebabkan adanya ketidakseimbangan antara karakteristik kepribadian karyawan dengan karakteristik pekerjaannya. Stres kerja menurut Marihot (2002) terjadi apabila seseorang mengalami ketegangan atau tekanan emosional karena adanya tuntutan yang sangat besar, terjadi hambatan dan kehilangan kesempatan yang sangat penting sehingga dapat mempengaruhi pikiran, emosi, dan kondisi fisik seseorang.

\section{Turnover Intention}

Robbins (2006), menyatakan bahwa (Voluntary turnover atau quit) disebabkan karena adanya beberapa faktor mengenai seberapa menarik pekerjaan yang dialami karyawan saat ini atau apakah tersedia alternatif pekerjaan lain.

\section{Pengaruh Work Family Conflict terhadap Stres Kerja}

Keberadaan stres kerja yang dialami oleh karyawati tentu saja tidak dapat dipisahkan dari sumber yang menyebabkan terjadinya stres kerja tersebut. Robbins (2007) menyatakan bahwa salah satu sumber stres kerja yang dialami oleh seorang karyawan adalah tuntutan peran. Judge et al., (Azazah, 2009) mengatakan bahwa work family conflict cenderung mengarah pada stress kerja karena ketika urusan pekerjaan mencampuri kehidupan keluarga, tekanan sering kali terjadi pada individu untuk mengurangi waktu yang dihabiskan dalam pekerjaan dan menyediakan lebih banyak waktu untuk keluarga. Sama halnya dengan konflik keluarga-pekerjaan dapat mengarah pada stres kerja dikarenakan banyaknya waktu yang dibutuhkan dalam menangani urusan pekerjaan dan ini merupakan sumber potensial terjadinya stres kerja.

H1: Work family conflict memiliki pengaruh positif signifikan terhadap stres kerja. 


\section{Pengaruh Beban Kerja terhadap Stres Kerja}

Menurut Suwatno (2014) yang termasuk dalam sumber stres kerja adalah beban kerja yang berlebihan. Beban kerja yang diberikan pada masing-masing karyawan harus sesuai dengan kemampuan dan kapasitas mereka dalam bekerja. Hal ini dilakukan agar hasil pekerjaan masing-masing karyawan memiliki kualitas yang maksimal.

Berdasarkan hal tersebut, hipotesis yang dirumuskan dalam penelitian ini adalah:

H2: Beban kerja berpengaruh positif terhadap Stres Kerja Karyawan.

\section{Pengaruh Work Family Conflict terhadap} Turnover Intention

Work family conflict merupakan suatu hal yang sulit dihindari oleh seorang karyawan terutama pada karyawan wanita. Konflik ini terjadi ketika adanya dua peran yang saling yaitu peran dalam keluarga dan dalam pekerjaan yang sama-sama harus diselesaikan. Karyawan yang tidak dapat berkonsentrasi terhadap tugas pekerjaannya dapat memutuskan untuk meninggalkan perusahaan. Ghayyur dan Jamal (2012) dalam penelitiannya menyatakan bahwa work family conflict berpengaruh positif dan signifikan dengan turnover intention.

Berdasarkan hal tersebut, hipotesis yang dirumuskan dalam penelitian ini adalah:

H3: Work family conflict berpengaruh positif terhadap turnover intention.

\section{Pengaruh Beban Kerja terhadap Turnover Intention}

Beban kerja mengacu pada jumlah pekerjaan yang diberikan untuk karyawan. Sejumlah peneliti telah mengidentifikasi hubungan positif antara beban kerja dan turnover intention. Quereshi et. al. (2013) menemukan bahwa terdapat hubungan yang signifikan antara beban kerja dan stres kerja, serta stres kerja dan turnover intention.

Berdasarkan hal tersebut, hipotesis yang dirumuskan dalam penelitian ini adalah:

H4: Beban kerja berpengaruh positif terhadap turnover intention karyawan

Pengaruh Stres Kerja terhadap Turnover Intention

Penelitian Qureshi et. al (2013) menemukan adanya hubungan positif stres kerja terhadap turnover intention, dimana dengan meningkatnya stres kerja juga diikuti dengan meningkatnya turnover intention. Stres muncul saat karyawan tidak mampu memenuhi apa yang menjadi tuntutan-tuntutan pekerjaan, ketidakjelasan apa yang menjadi tanggung jawab pekerjaan, kekurangan waktu untuk menyelesaikan tugas, tidak ada dukungan fasilitas untuk menjalankan pekerjaan, tugas-tugas yang saling bertentangan, merupakan contoh pemicu stres.

Berdasarkan hal tersebut, hipotesis yang dirumuskan dalam penelitian ini adalah:

H5: Stres kerja berpengaruh positif terhadap turnover intention karyawan

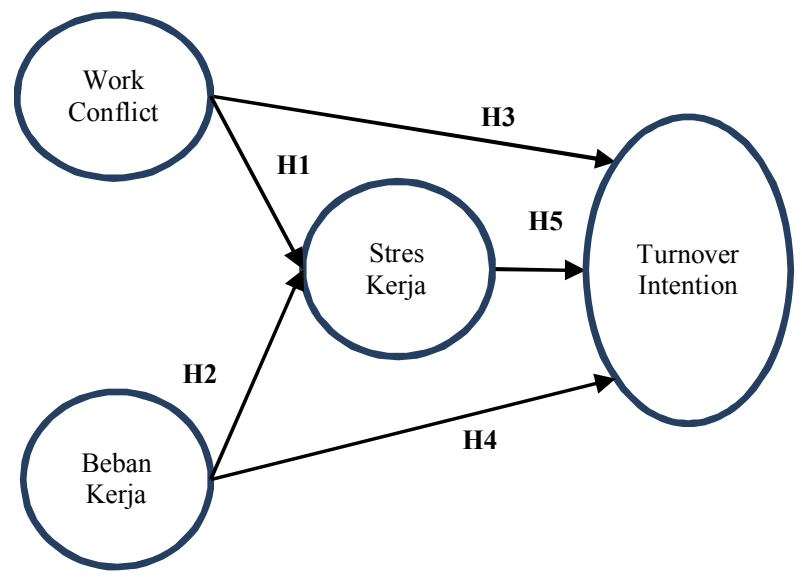

Gambar 1. Model Hipotesis

\section{Metode}

\section{Populasi dan Sampel}

Populasi dalam penelitian ini adalah karyawan wanita dengan status sudah menikah yang bekerja pada PT. BNI Tbk 
wilayah Semarang, yaitu 1.516 orang. Teknik pengambilan sampel yang digunakan purposive sampling. Sekaran (2006) menyatakan bahwa purposive sampling adalah salah satu teknik sampling non random dimana penentuan sampel berdasarkan pertimbangan tertentu, antara lain: (1) Karyawan yang dijadikan sebagai responden merupakan karyawan dengan status tetap dalam perusahaan; (2) Karyawan wanita dan telah menikah; (3) Karyawan dengan masa kerja minimal dua tahun; (4) Karyawan yang mempunyai keinginan untuk keluar dari pekerjaannya. Sehingga dalam penelitian ini ditetapkan sampel sebanyak 151 karyawan wanita yang diambil dari keseluruhan cabang yang berada di kantor wilayah Semarang.

\section{Teknik Analisis}

Analisis data digunakan untuk menjawab berbagai pertanyaan penelitian dan memecahkan masalah penelitian.Untuk menguji $\mathrm{H} 1$ hingga $\mathrm{H} 5$ dalam penelitian ini digunakan Structural Equation Model dalam program AMOS.

\section{Hasil dan Pembahasan}

Analisis Faktor Konfirmatori (Confirmatory Factor Analysis) untuk Eksogen Validitas Diskriminan ditunjukkan pada Tabel 2.

Tabel 2. Hasil Pengujian Konstruk Eksogen Validitas Diskriminan

\begin{tabular}{llll}
\hline $\begin{array}{l}\text { Goodness } \\
\text { of Fit } \\
\text { Indeks }\end{array}$ & $\begin{array}{l}\text { Cut-off } \\
\text { Value }\end{array}$ & $\begin{array}{l}\text { Hasil } \\
\text { Analisis }\end{array}$ & $\begin{array}{l}\text { Evaluasi } \\
\text { Model }\end{array}$ \\
\hline Chi & $<15,507$ & 12,776 & Baik \\
Square & df 8 & & \\
Probability & $\geq 0.05$ & 0,120 & Baik \\
RMSEA & $\leq 0.08$ & 0,063 & Baik \\
GFI & $\geq 0.90$ & 0,973 & Baik \\
AGFI & $\geq 0.90$ & 0,928 & Baik \\
CMIN/df & $\leq 2,00$ & 1,579 & Baik \\
& & & \\
TLI & $\geq 0.95$ & 0,974 & Baik \\
CFI & $\geq 0.95$ & 0.986 & Baik \\
\hline
\end{tabular}

Sumber: Data primer, diolah (2018)

Pada tabel 3. disajikan tentang hasil pengujian konstruk endogen yaitu:
Tabel 3. Hasil Pengujian Konstruk Endogen

\begin{tabular}{llll}
\hline $\begin{array}{l}\text { Goodness } \\
\text { of Fit } \\
\text { Indeks }\end{array}$ & $\begin{array}{l}\text { Cut-off } \\
\text { Value }\end{array}$ & $\begin{array}{l}\text { Hasil } \\
\text { Analisis }\end{array}$ & $\begin{array}{l}\text { Evaluasi } \\
\text { Model }\end{array}$ \\
\hline $\begin{array}{l}\text { Chi } \\
\text { Square }\end{array}$ & $<15,507$ & 18,862 & Marjinal \\
df 8 & & \\
Probability & $\geq 0.05$ & 0,016 & Marjinal \\
RMSEA & $\leq 0.08$ & 0,095 & Baik \\
GFI & $\geq 0.90$ & 0,962 & Baik \\
AGFI & $\geq 0.90$ & 0,900 & Baik \\
CMIN/df & $\leq 2,00$ & 2,358 & Mariinal \\
TLI & $\geq 0.95$ & 0,940 & Baik \\
CFI & $\geq 0.95$ & 0.968 & Baik \\
\hline
\end{tabular}

Sumber: Data primer, diolah (2018)

Tabel 4. Normalitas Data

\begin{tabular}{|l|llllll|}
\hline Variable & $\min$ & $\max$ & skew & c.r. & kurtosis & c.r. \\
\hline x16 & 4,000 & 9,000 &, 040 &, 200 &,- 502 & $-1,259$ \\
x15 & 3,000 & 9,000 &,- 415 & $-2,080$ &,- 152 &,- 381 \\
x14 & 4,000 & 10,000 &, 137 &, 688 &,- 657 & $-1,647$ \\
x10 & 3,000 & 10,000 &, 010 &, 051 &,- 067 &,- 168 \\
x11 & 3,000 & 10,000 &, 053 &, 266 &,- 513 & $-1,287$ \\
x12 & 3,000 & 10,000 &,- 053 &,- 265 &,- 153 &,- 384 \\
x7 & 3,000 & 9,000 &,- 460 & $-2,305$ &,- 067 &,- 167 \\
x8 & 3,000 & 10,000 &, 096 &, 484 &,- 077 &,- 192 \\
x9 & 3,000 & 10,000 &, 027 &, 134 &,- 519 & $-1,301$ \\
x3 & 3,000 & 10,000 &,- 367 & $-1,842$ &,- 766 & $-1,920$ \\
x2 & 4,000 & 10,000 &,- 148 &,- 741 &,- 418 & $-1,049$ \\
x1 & 4,000 & 10,000 &,- 088 &,- 439 &,- 191 &,- 480 \\
Multivariate & & & & & $-2,861$ &,- 959 \\
\hline
\end{tabular}

Sumber: Data primer, diolah (2017)

Data penelitian telah memenuhi syarat normalitas data dikarenakan seperti yang nampak pada tabel 4. di atas tidak terdapat nilai CR skewness diluar +_2,58.

\section{Multivariate Outliers}

Hasil dari multivariate outliers tersebut disajikan pada Tabel 5 di bawah ini:

Tabel 5. Multivariate Outliers

\begin{tabular}{ccccc}
\hline $\begin{array}{l}\text { Observation } \\
\text { number }\end{array}$ & \multicolumn{2}{l}{$\begin{array}{l}\text { Mahalanobis d- } \\
\text { squared }\end{array}$} & $\mathrm{p} 1$ & $\mathrm{p} 2$ \\
\hline 47 & 27,500 &, 007 &, 629 \\
151 & 22,678 &, 031 &, 947 \\
47 & 27,500 &, 007 &, 629 \\
-- & -- & -- & -- \\
-- & -- & -- & -- \\
85 & 9,994 &, 616 &, 231 \\
\hline
\end{tabular}




\begin{tabular}{cccc}
\hline $\begin{array}{l}\text { Observation } \\
\text { number }\end{array}$ & $\begin{array}{l}\text { Mahalanobis d- } \\
\text { squared }\end{array}$ & $\mathrm{p} 1$ & $\mathrm{p} 2$ \\
\hline 69 & 9,870 &, 627 &, 265 \\
82 & 9,820 &, 632 &, 245 \\
\hline
\end{tabular}

Sumber: Data primer, diolah (2018)

Analisis Structural Equation Model (SEM)

Pada tahapan ini dilakukan uji kesesuaian dan uji statisik, yang hasilnya dapat dilihat pada Gambar 4.

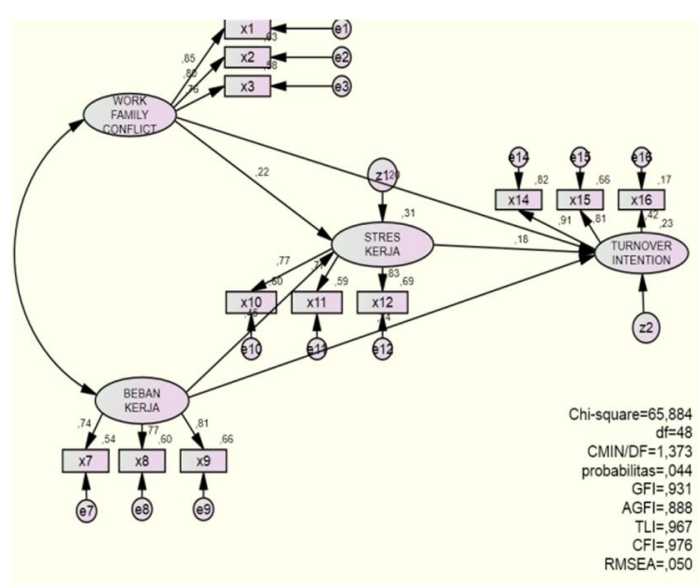

\section{Gambar 4. Structural Equation Model (Path Diagram)}

Sumber: Data primer, diolah (2018)

Pada Tabel 6 di bawah ini disajikan tentang hasil pengujian kelayakan Structural Equation Model (SEM).

Tabel 6. Hasil Pengujian Kelayakan Model Structural Equation Model (SEM)

\begin{tabular}{|l|l|l|l|}
\hline $\begin{array}{l}\text { Goodness of } \\
\text { Fit Indeks }\end{array}$ & $\begin{array}{l}\text { Cut-off } \\
\text { Value }\end{array}$ & $\begin{array}{l}\text { Hasil } \\
\text { Analisis }\end{array}$ & $\begin{array}{l}\text { Evaluasi } \\
\text { Model }\end{array}$ \\
\hline $\begin{array}{l}\text { Chi } \\
\text { Square }\end{array}$ & $\begin{array}{l}<65,171 \\
\text { df } 48\end{array}$ & 65,884 & Marjinal \\
\hline Probability & $\geq 0.05$ & 0,044 & Marjinal \\
\hline RMSEA & $\leq 0.08$ & 0,050 & Baik \\
\hline GFI & $\geq 0.90$ & 0,931 & Baik \\
\hline AGFI & $\geq 0.90$ & 0,888 & Marjinal \\
\hline CMIN/df & $\leq 2,00$ & 1,373 & Baik \\
TLI & $\geq 0.95$ & 0,967 & Baik \\
\hline CFI & $\geq 0.95$ & 0,976 & Baik \\
\hline
\end{tabular}

Sumber: Data primer, diolah (2018)
Tabel 7. Regression Weight Structural Equational Model

\begin{tabular}{|c|c|c|c|c|c|c|}
\hline & & & $\begin{array}{l}\text { Estim } \\
\text { ate }\end{array}$ & S.E. & C.R. & $\mathrm{P}$ \\
\hline Stres_kerja & & $\begin{array}{l}\text { Work_famil } \\
\text { y_conflict }\end{array}$ & ,209 & $\begin{array}{l}, 08 \\
9\end{array}$ & $\begin{array}{l}2,34 \\
7\end{array}$ & ,019 \\
\hline Stres_kerja & $\begin{array}{l}<- \\
--\end{array}$ & Beban_kerja &, 361 & $\begin{array}{l}, 08 \\
1\end{array}$ & $\begin{array}{l}4,47 \\
2\end{array}$ & $* * *$ \\
\hline $\begin{array}{l}\text { Turnover_inte } \\
\text { ntion }\end{array}$ & $\begin{array}{l}<- \\
--\end{array}$ & Stres_kerja & ,232 & $\begin{array}{l}, 14 \\
3\end{array}$ & $\begin{array}{l}1,61 \\
6\end{array}$ & , 106 \\
\hline $\begin{array}{l}\text { Turnover_inte } \\
\text { ntion }\end{array}$ & $\begin{array}{l}<- \\
--\end{array}$ & $\begin{array}{l}\text { Work_famil } \\
\text { y_conflict }\end{array}$ & ,244 & $\begin{array}{l}, 11 \\
7\end{array}$ & $\begin{array}{l}2,08 \\
4\end{array}$ & ,037 \\
\hline $\begin{array}{l}\text { Turnover_inte } \\
\text { ntion }\end{array}$ & $\begin{array}{l}<- \\
--\end{array}$ & Beban_kerja & ,248 & $\begin{array}{l}, 11 \\
2\end{array}$ & $\begin{array}{l}2,20 \\
8\end{array}$ &, 027 \\
\hline
\end{tabular}

Sumber: Data primer, diolah (2018)

\section{Kesimpulan dan Saran}

Kesimpulan: (1) Hasil pengujian pengaruh work family conflict terhadap stres kerja dapat disimpulkan work family conflict pengaruh positif terhadap stres kerja; (2) Hasil pengujian pengaruh beban kerja terhadap stres kerja dapat disimpulkan beban kerja berpengaruh positif terhadap stres kerja; (3) Hasil pengujian pengaruh work family conflict terhadap turnover intention dapat disimpulkan work family conflict berpengaruh positif terhadap turnover intention; (4) Hasil pengujian pengaruh beban kerja terhadap turnover intention dapat disimpulkan beban kerja berpengaruh positif terhadap turnover intention; (5) Hasil pengujian pengaruh stres kerja terhadap turnover intention dapat disimpulkan stres kerja tidak berpengaruh positif terhadap turnover intention.

Saran yang diberikan adalah: (1) Penelitian mendatang dilakukan tidak hanya dari satu sudut pandang karyawan wanita saja, melainkan dianjurkan sekaligus dari dua sudut pandang, yaitu perspektif jajaran pimpinan / managemen puncak / manager dan juga sudut pandang karyawan itu sendiri; (2) Penelitian mendatang dapat menggunakan sampel tidak hanya dari Semarang dan sekitarnya saja melainkan dapat juga menggunakan sampel dari unit kerja kota lain sehingga dapat lebih menggambarkan atau memprediksi masalah turnover intention karyawan secara keseluruhan dalam suatu perusahaan; (3) Penelitian mendatang agar dapat dilakukan dengan memanfaatkan sistem informasi internal yang disebarkan keseluruh karyawan melalui email karyawan yang khusus ditujukan kepada karyawan wanita yang 
memang memiliki keinginan untuk berpindah kerja.

\section{Daftar Referensi}

Abbasi, Tajmal Farooq. (2015). Impact of Work Overload on Stress, Job Satisfaction, and Turnover Intentions with Moderating Role of Islamic Work Ethics. Management Studies and Economic Systems (MSES), 2 (1), 27-37.

Alsam, Naeem, et al. (2013). The Impact of Work Family Conflict on Turnover Intentions: An Empirical Evidence from Pakistan. World Applied Sciences Journal, 24 (5): 628-633.

Arshadi, Nasrin and Damiri, Hojat. (2012). The Relationship of Job Stress with Turnover Intention and Job Performance: Moderating Role of OBSE. ProcediaSocial and Behavioral Sciences 84, pp: 706-710.

Aslam, Rabia, et al. (2011). Work-Family Conflicts: Relationship between WorkLife Conflict and Employee Retention A Comparative Study of Public and Private Sector Employees. Interdisciplinary Journal of Research in Business. Vol. 1, Issue. 2, pp.18-29.

Buckingham, Donald A. (2004). Associations among stress, work overload, role conflict and self efficacy in maine principals. University of Maine. Vol. 6, No. 1, pp 1-250.

Chen CC, Choi J, Zou Y. (2000). Sources of work-family conflict: A Sino-U.S. comparison of the effects of work and family demands. Acad Manage, J;43:113-23.

Crouter, Ann C., Mathew F. Bumpus, Melissa R. Head, dan Susan McHale. (2001). Implications of overwork for the quality of mens family relationship. ProQuest. Vol. 63, No. 2, pp 404-416. Diambil dari: http://bmjopen.bmj.com// (diakses 6 September 2017).
Frone, Russell dan Cooper. (1992). Relationship Between Job and Family Satisfaction. Journal of Management, 565-579.

Hang-yue, Ngo, Sharon Foley and Raymond Loi. (2005). Work role stressors and turnover intentions: a study of professional clergy in Hong Kong. Int. J. of Human Resource Management, 16:11, 2133-2146.

Ilyas, Yaslis. (2000). Perencanaan Sumber Daya Manusia PT (Teori, Metode dan Formula). Jakarta: Pusat Kajian Ekonomi Informasi FKM-UI Depok.

Indriantoro, Nur dan Suwandi. (1999). Metodologi Penelitian Bisnis untuk Akuntansi dan Manajemen. BPFE: Yogyakarta.

Judge, T.A. and J.A. Colquitt. (2004). Organizational Justice and Stress: The Mediating Role of Work-Family Conflict. Journal of Applied Psychology, 89(3), pp: 394-404.

Lu, Yong, et al. (2017). The relationship between job satisfaction, work stress, work-family conflict, and turnover intention among physicians in Guangdong, China: a cross-sectional study.

Mangkunegara, A.A. Anwar Prabu. (2008). Manajemen Sumber Daya Manusia Perusahaan. Bandung: Remaja Rosdakarya.

Mangkunegara. (2008). Evaluasi Kinerja SDM. Bandung: PT Refika

Nasrudin, A.M. dan S. Kumaresan. (2005). Organisational Stressor. Singapore Management Review. Vol. 27 (2): pp 6379.

Parasuraman, Valarie A. Zheitaml and Leonard L. Berry. (1998). Reassesment of Expectation as a Comparison Standard in Measuring Service Quality: Implication for further research. Journal 
of Marketing. Chicago. Vol. 58, No. 1.

Pearson, Ann, J. Michael Pearson, dan Chris Griffin. (2009). Innovating with Technology: The Impact of Overload, Autonomy, and Work and Family Conflict. JITTA. Vol. 9, No. 4, pp 41-65.

Pradana, Andika dan Imam Salehudin. (2013). Role of work overload toward turnover intention among newly hired public accountants. Munich Personal RePEc Archive. Paper No. 54342.

Putra, Muhammad Taufan Permana dan Unika Prihatsanti. (2016). Hubungan Antara Beban Kerja dengan Intensi Turnover pada Karyawan di PT. X Semarang. Jurnal Empati. Vol. 5 (2), 303-307.

Quereshi, M. I., Iftikhar, M., Abbas, S.G., Khan, K., Zaman, K. (2013). Relationship Between Job Stress, Workload, Environment and Employees Turnover Intentions: What We Know, What Should We Know. Jurnal of Management Info, 23(6).

Robbins, Stephen P. (2006). Perilaku Organisasi. Jakarta: PT Indeks.

Robbins, Stephen P. (2007). Perilaku Organisasi. Jakarta: Salemba Empat.

Robbins, Stephen P. dan Judge. (2007). Perilaku Organisasi. Jakarta: Salemba Empat.

Santoso, Singgih. (2000). Buku Latihan SPSS Statistik Parametrik. Jakarta: PT Elex Media Komputindo.

Schultz, D., Schultz, S E. (2006). Psychology \& Work Today Ninth Edition. New Jersey: Pearson Education. Inc.

Sekaran, Uma. (2006). Research Methods For Business, Edisi 4 buku 2. Jakarta: Salemba Empat.

Siagian, Sondang. (2008). Manajemen Sumber Daya Manusia. Jakarta: Bumi Aksara.
Sugiyono. (2002). Statistika Untuk Penelitian. Bandung: CV. Alfabeta.

Sugiyono. (2010). Metode Penelitian Pendidikan Pendekatan Kuantitatif, Kualitatif, dan R\&D. Bandung: CV. Alfabeta.

Suwatno dan Donni Juni Priansa. (2014). Manajemen SDM dalam Organisasi Publik dan Bisnis. Bandung: Alfabeta.

Wallace, Jean E. (2005). Job stress, depression, and work to family conflict. Relations Industrialeses. Vol. 1, No. 3, pp 510-568.

Widyaningrum, A.I., Y. Pongtuluran, dan I. Tricahyadinata. (2013). Pengaruh Konflik Peran Ganda dan Stres Kerja Terhadap Kinerja Karyawan Wanita Pada Swalayan Era Mart 5000 Di Samarinda. Jurnal Fakultas Ekonomi Universitas Mulawarman.

Wirakristama, Richardus Chandra. (2011). Analisis Pengaruh Konflik Peran Ganda (Work Family Conflict) Terhadap Kinerja Karyawan Wanita Pada PT Nyonya Meneer Semarang Dengan Stres Kerja Sebagai Variabel Intervening. Skripsi. Semarang: Fakultas Ekonomi Universitas Diponegoro.

Yang, N., Chen, C. C., Choi, J., \& Zou Y. (2000). Sources Of Work-Family Conflict: A Sino-U.S. Comparison of The Effect Of Work And Family Demands. Academy of Management Journal. 43: 113-123.

Yang, Yi Lee. (2000). Performance and Quality of Work Life. Journal of Organizational Change Management. Vol. 13., p.389-400. 